NASA Technical Memorandum 4605

\title{
On the Use of Controls for Subsonic Transport Performance Improvement: Overview and Future Directions
}

Glenn Gilyard and Martín España Dryden Flight Research Center Edwards, California

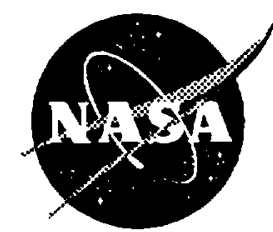

National Aeronautics and Space Administration Office of Management Scientific and Technical Information Program 



\title{
ON THE USE OF CONTROLS FOR SUBSONIC TRANSPORT PERFORMANCE IMPROVEMENT: OVERVIEW AND FUTURE DIRECTIONS
}

\author{
Glenn Gilyard" and Martín España ${ }^{\dagger}$ \\ NASA Dryden Flight Research Center \\ P.O. Box 273 \\ Edwards, Califomia 93523-0273
}

\begin{abstract}
Increasing competition among airline manufacturers and operators has highlighted the issue of aircraft efficiency. Fewer aircraft orders have led to an all-out efficiency improvement effort among the manufacturers to maintain if not increase their share of the shrinking number of aircraft sales. Aircraft efficiency is important in airline profitability and is key if fuel prices increase from their current low. In a continuing effort to improve aircraft efficiency and develop an optimal performance technology base, NASA Dryden Flight Research Center developed and flight tested an adaptive performance seeking control system to optimize the quasi-steady-state performance of the F-15 aircraft. The demonstrated technology is equally applicable to transport aircraft although with less improvement. NASA Dryden, in transitioning this technology to transport aircraft, is specifically exploring the feasibility of applying adaptive optimal control techniques to performance optimization of redundant control effectors. A simulation evaluation of a preliminary control law optimizes wing-aileron camber for minimum net aircraft drag. Two submodes are evaluated: one to minimize fuel and the other to maximize velocity. This paper covers the status of performance optimization of the current fleet of subsonic transports; available integrated controls technologies are reviewed to define approaches using active controls. A candidate control law for adaptive performance optimization is presented along with examples of algorithm operation.
\end{abstract}

\footnotetext{
-Aerospace Engineer. AIAA Member.

${ }^{\dagger}$ Research Associate of the National Research Council. AlAA Member.

Copyright $@ 1994$ by the American Institute of Aeronautics and Astronautics, Inc. No copyright is asserted in the United States under Tile 17 U.S. Code. The U.S. Government has a royalty-free license to exercise all rights under the copyright claimed herein for Govemmental purposes. All other rights are reserved by the copyright owner.
}

\section{Nomenclature}

$\begin{array}{ll}\text { ACEE } & \text { aircraft energy efficiency } \\ \text { AFTI } & \text { advanced fighter technology integration } \\ \text { CCC } & \text { cruise camber control } \\ C_{L} & \text { coefficient of lift } \\ \text { c.g. } & \text { center of gravity } \\ g & \text { acceleration caused by gravity } \\ \text { HIDEC } & \text { highly integrated digital electronic control } \\ L / D & \text { lift-to-drag ratio } \\ \text { LE } & \text { leading edge } \\ M & \text { Mach number } \\ \text { MAW } & \text { mission adaptive wing } \\ \text { MCC } & \text { maneuver camber control } \\ \text { PSC } & \text { performance-seeking control } \\ \text { TE } & \text { trailing edge }\end{array}$

\section{Introduction}

Increasing competition among airline manufacturers and operators has highlighted the issue of aircraft efficiency. This issue is timely because of a worldwide economic recession, which means fewer passengers, heightened competition, fewer aircraft orders, and results in reduced profits (or losses) for manufacturers and airlines. Fewer aircraft orders have led to an all-out efficiency improvement effort among the manufacturers to maintain if not increase their share of the shrinking number of aircraft sales. Aircraft efficiency is an important factor in airline profitability and is the key factor if fuel prices increase from their çurrent low. A 1-percent improvement in lift to drag ratio $(L / D)$ for the U.S. fleet of wide-body transports can result in savings of approximately $\$ 100$ million per year and an additional $\$ 20$ million per year for each $\$ 0.10 /$ gal increase in fuel price.

A significant amount of transport efficiency technology was developed in the late 1970's, 1980's and has 
continued into the early 1990's. The aircraft energy efficiency (ACEE) program explored the areas of maneuver load control, elastic mode suppression, gust load alleviation, ${ }^{1}$ relaxed static stability, ${ }^{2}$ and the design of a reduced-area horizontal tail. ${ }^{3}$ The advanced fighter technology integration (AFTI)/F-111 mission adaptive wing (MAW) program developed and demonstrated variablecamber control for optimization of cruise and maneuver flight conditions. ${ }^{46}$ Airbus Industrie (a consortium of European companies) has implemented a load alleviation system in the A320 aircraft at the design stage, implemented an active center-of-gravity control system, explored improved accuracy sideslip control, ${ }^{10}$ and performed preliminary design work for implementation of variable camber into the A330/A340 aircraft. ${ }^{11,12}$ American manufacturers also are actively involved in efficiency enhancement and have explored fixed-point rerigging of redundant control effectors to minimize airframe drag.

NASA Dryden Flight Research Center has also supported research in the area of performance improvements for well over a decade. ${ }^{13-15}$ The most recent effort involved developing and flight testing an adaptive performance seeking control (PSC) system with the objective of optimizing the quasi-steady-state performance of the F-15 HIDEC research aircraft. The PSC system has the following optimization modes: (a) minimum fuel flow at constant thrust, (b) minimum turbine temperature at constant thrust, and (c) maximum thrust. Subsonic and supersonic flight testing of the PSC algorithm has been concluded at NASA Dryden and reported. ${ }^{16}$ At the conceptual level, the technology demonstrated in the PSC program is equally applicable to transport aircraft, although not with the same percentage of improvements because transports operate over a much narrower envelope and start nearer optimum cruise performance than do fighter aircraft. In addition, the algorithm used for PSC concentrated on the propulsion system, was heavily based on a priori model data and equations, and used linear programming for the solution.

NASA Dryden is currently active in transitioning performance improvement technology, much of which was developed on fighter aircraft, to transport aircraft. The algorithm demonstrated on the PSC program, while suitable as an early demonstration on an aircraft with large benefits to be accrued and with detailed models available, is not suitable for implementing for performance optimization on subsonic transports primarily because of the much smaller benefits accruable. As such, NASA Dryden is exploring the application of measurement-based adaptive optimal control for performance improvement using redundant control effector capability. As the terminology implies, adaptive optimization compensates for all unique characteristics of the system being optimized by continuously feeding back measurements of parameters that reflect the optimization objective such as fuel flow (minimize) or velocity (maximize). For example, symmetric aileron deflection can be applied to optimally recamber the wing for all aircraft configurations and flight conditions. Of course, flightpath constraints, such as altitude and speed, must be controlled through inner-loop horizontal stabilizer and throttle control.

A feasibility evaluation study of an adaptive control law has been conducted on a high-fidelity, nonlinear simulation of the B-720 aircraft. The prototype control law optimizes wing-aileron camber for minimum aircraft drag at a given flight condition. This technology is readily applicable to selected current generation aircraft and to the entire next generation of fly-by-wire aircraft and could well be a requirement for future designs such as the new large aircraft. $^{17}$ Because of aggressive competition among manufacturers and airlines, adaptive performance optimization will play an important role in improving economic factors by maximizing aircraft performance; early research is required for timely technology transition.

This paper covers one facet of the global problem of improving the performance of subsonic transport aircraft -the general area of application of integrated-active controls technology to performance optimization (drag reduction) through configuration optimization. The status of performance improvement for the current fleet of subsonic transports and integrated controls technologies available is reviewed with the intent of defining approaches to performance optimization using active controls. A candidate control law for adaptively optimizing performance is presented along with examples of system operation. Espana and Gilyard present a more detailed discussion of the algorithm and design issues for application to subsonic transport aircraft. ${ }^{18}$

\section{Aircraft Efficiency Survey}

Current subsonic transport design results in a pointdesign configuration with the exception of flap usage at low-speed flight conditions. By necessity, the final configuration is a major compromise among a multitude of design considerations. Additionally, the final design only provides near optimal performance for specifically defined flight profiles and results in the aircraft flying at its best performance design condition very seldom or only by chance. In the clean configuration (gear retracted, no flap or slat deflections), no additional configuration changes remain to optimize performance for the vast range of practical constraints. Such constraints include air traffic control directives (speed and altitude), loading (cargo and fuel), 
center of gravity (c.g.), flight length, variations in manufacturing, aging, and asymmetries.

No aircraft currently has adaptive configuration optimization. However, manual configuration optimization is attempted on essentially all transport aircraft during takeoff, approach, and landing situations when flaps are used to improve or optimize low-speed lift requirements. Adaptive performance optimization is the natural extension of what is currently done manually to improve lift characteristics during low-speed flight. Airframe manufacturers are beginning to explore fixed-point rerigging of control surfaces for drag minimization on their latest aircraft models.

\section{Status of Current Transport Performance Optimization}

Aircraft currently use the flight management system as the main tool to obtain some degree of in-flight performance optimization. The application of this technology is obviously a step in the right direction and provides significant benefits over a crewmember using charts and tables in real time to optimize the aircraft. 19 The term "optimization" is used widely and loosely and, in a discussion of this nature, consistency and the ability to distinguish the different types are important. The above-mentioned manual and flight management system optimization are best referred to as "trajectory optimization." Both methods are based on predicted characteristics of the aircraft (models or charts) as opposed to actual characteristics. To be accurate, therefore, the above-mentioned optimization should be referred to as "model-based trajectory optimization." The differences among models and the actual aircraft should be small, but due to inaccurate modeling, errors, actual aircraft changes over time, or all three, differences could be important. If the actual performance-related characteristics of a given specific aircraft can be determined in flight, that information can be exploited to gain performance improvements over what is termed "model-based trajectory optimization."

\section{Related Performance Optimization Research}

The first significant application of active controls to the modem wide-body transport was made by Lockheed-California Co. (Burbank, CA) on the L-1011 aircraft in the early 1970 's. The objective was to actively control the ailerons for wing load alleviation so that the takeoff weight of the aircraft could be increased. Following a worldwide fuel crisis in the mid-1970's, many research activities were conducted in the late 1970's and early 1980's in the area of performance improvement as part of NASA's ACEE program. The AFTI/F-111 MAW program was also conducted in the mid-1980's as part of the AFTI effort. This program demonstrated that variablecamber technology has significant potential for application to transport aircraft.

The KC-135 winglet program was a major flight research effort conducted in the late 1970's and early 1980's and was directed at documenting drag reduction potential of winglets. The flight program was very successful and demonstrated fuel mileage improvements of between 4.4 and 7.2 percent at $\operatorname{Mach}(M)=0.78$. ${ }^{20}$ However, this program did not involve the use of active controls and as such, will not be discussed further in this report.

\section{ACEE Activities}

A major effort of the ACEE program involved a series of joint NASA Langley Research Center and Lockheed programs many of which were flight tested on a modified L-1011. Early research, built on previous Lockheed experience, explored the benefits of maneuver load control, elastic mode suppression, and gust load alleviation. This research was followed by a relaxed static stability study that included the design of an advanced pitch control system. Finally the design of a reduced-area horizontal tail was explored; this last program was not taken to flight but did illustrate the complexities of designing aerodynamics for minimum drag. ${ }^{3}$ This last study indicated the difficulty in achieving an optimal design, thus highlighting the desirability of having adaptive optimization capability to accommodate an aerodynamic design that is, of necessity, a compromise.

\section{AFTI/F-111 Activities}

Figure 1 presents the AFTI/F-111 MAW configuration. The MAW's primary feature is its leading-edge (LE) and trailing-edge (TE) smooth variable-camber capability. The MAW demonstrated many modes of operation designed to enhance fighter capability. ${ }^{46}$ Two of these modes also have significant application to transport type aircraft. These are the cruise camber control (CCC) mode, designed for real-time drag reduction and the maneuver camber control (MCC) mode, designed to maximize $L / D$. While the concept of these modes was successfully demonstrated in flight, both modes had limitations relative to practical implementation whether it be for fighters or transports. The MCC mode required accurate models that were stored in table lookup form onboard the aircraft, and the CCC mode had a primitive optimization algorithm, not 


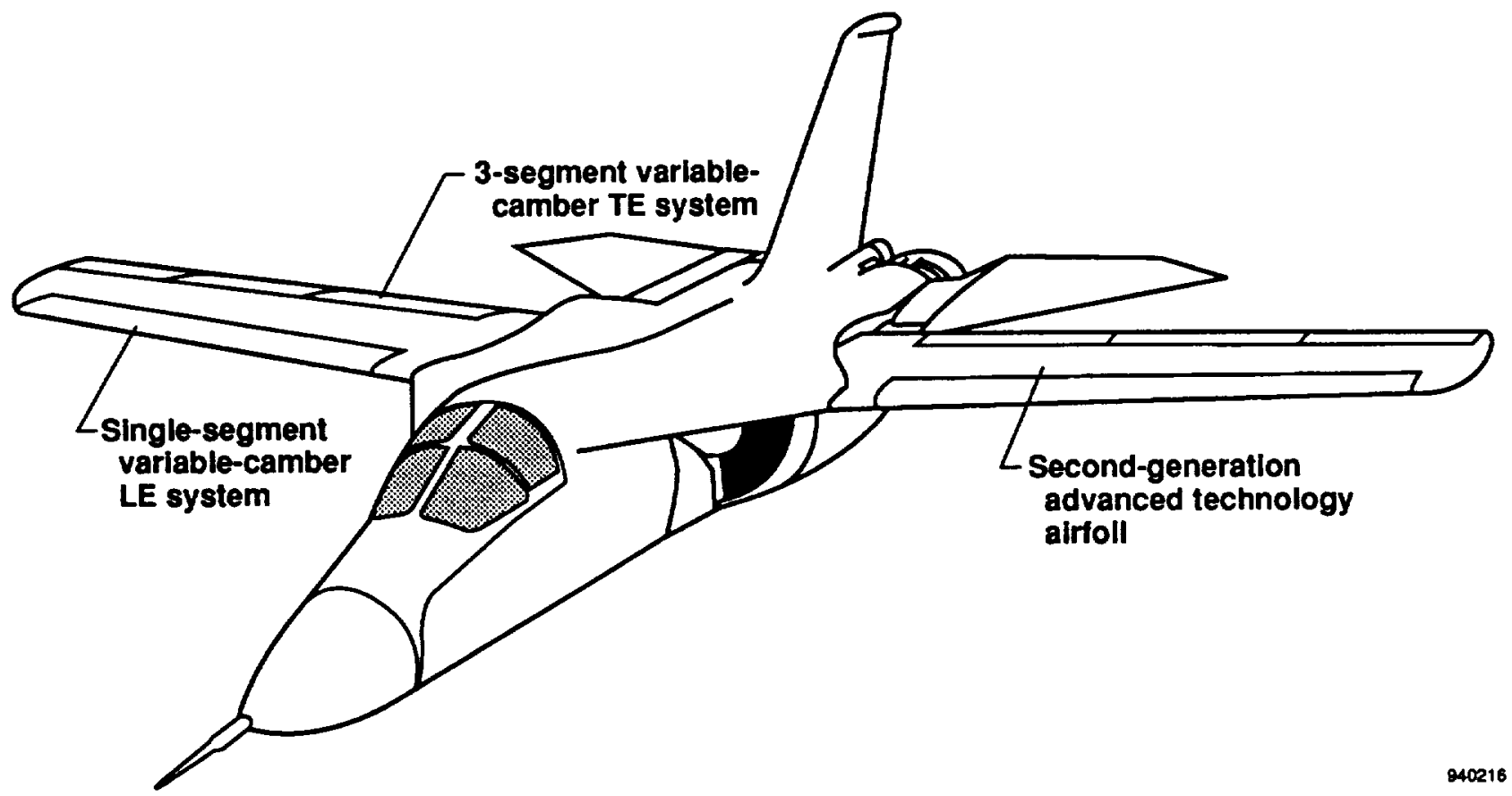

Figure 1. MAW modifications to F-111.

suited for the low levels of drag improvements available on transport aircraft. Figure 2 presents a set of trimmed flight test results illustrating the drag reduction capability through variable camber over the baseline aircraft results for two different Mach numbers. The drag reduction varied from about 8 percent at the design cruise point

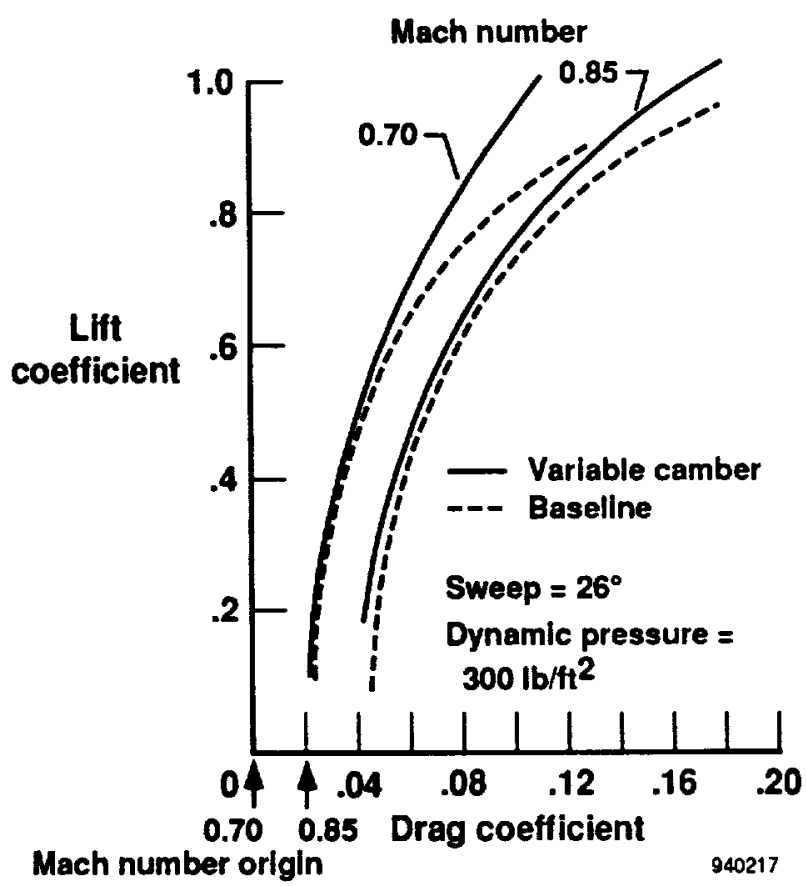

Figure 2. Flight-determined drag polar comparison.
$\left(C_{L}=0.4, M=0.85\right)$ to over 20 percent at an off-design condition $\left(C_{L}=0.8, M=0.70\right)$.

The X-29 experimental research aircraft had three pitch surfaces (canard, flaperon, and strake flaps) with the flaperon having segmented variable-camber capability. Scheduling was used to achieve a degree of predicted performance optimization.

\section{Airbus Industrie Activities}

The Airbus Industrie consortium of companies has become a strong competitor in the commercial transport arena. The consortium has been open to applying new advanced technologies to improve their product line. A host of related papers and reports discussing advanced technology issues is available. ${ }^{7-12,23-25}$

Airbus has explored numerous areas using active controls for drag reduction. Among these are active c.g. control, active load control, variable-camber control, and active sideslip control.

The consortium has developed and implemented an active c.g. control system to minimize trim drag on selected A-300-series aircraft. This system involves an accurate fully loaded calculation of the pretakeoff c.g. Then, once airborne, the c.g. location is calculated in real time and is controlled to the aft certified limit using fuel transfer capability. A significant performance benefit can clearly be accrued by keeping the c.g. at its aft limit. Figure 3 presents an example of actual system operation 


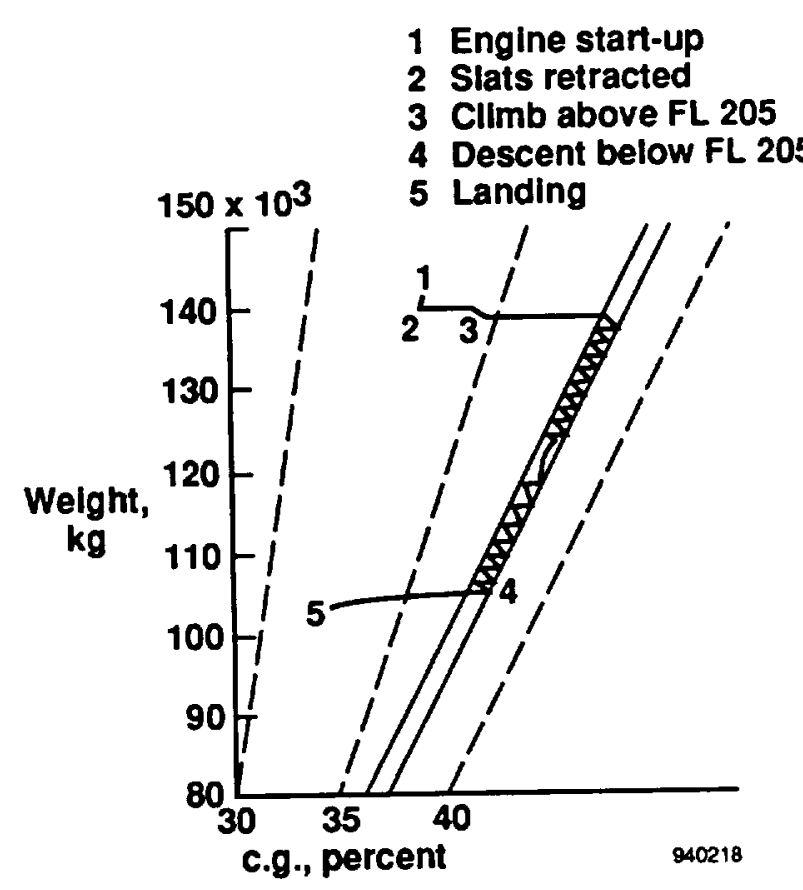

Figure 3. Active c.g. control for an A-310-300 transport.

on an A-310-300. As observed, at altitudes above 20,500 $\mathrm{ft}$, c.g. is controlled to the aft c.g. limit to less than 1 -percent deviation, which results in 2-percent less fuel burn.

Airbus has also followed up on the early work done by Lockheed ${ }^{2}$ by designing a wing load alleviation system into the A-320 aircraft from its inception, thus maximizing its synergistic benefits. For instance, wing weight has been reduced by actively controlling wing bending moments.

In an aggressive and challenging application of active controls technology, Airbus seriously considered applying variable camber to their A-330/A-340 series. Extensive wind-tunnel testing was conducted along with some flight experiments. The benefits of variable camber include the following: ${ }^{23}$

- Improved aerodynamic efficiency (improved $L / D$ )

- Increased Mach capability

- Improved buffet boundary

- Increased operational flexibility

- Reduced structural weight

- Reduced fuel burn

- Increased aircraft development potential

Figure 4 illustrates that, even at the design point of a state-of-the-art conventional wing, the variable-camber feature provides higher $L / D$ ratios. Variable camber produced $L / D$ increases of between 3 and 9 percent and a buffet boundary increase of 12 percent. In addition, future application of advanced laminar flow techniques would benefit by trailing-edge control, which permits chordwise extension of laminar flow. ${ }^{24}$

It was only at the last minute, so to speak, that the variable-camber feature was not included on the production aircraft. The proposed variable-camber design did not substantially address the issue of real-time adaptive optimization.

Airbus has also explored accurate determination of effective aircraft sideslip so that the aircraft can be controlled to the minimum drag due to sideslip flight condition. Drag due to sideslip is a quadratic function and becomes increasingly important as errors in sideslip
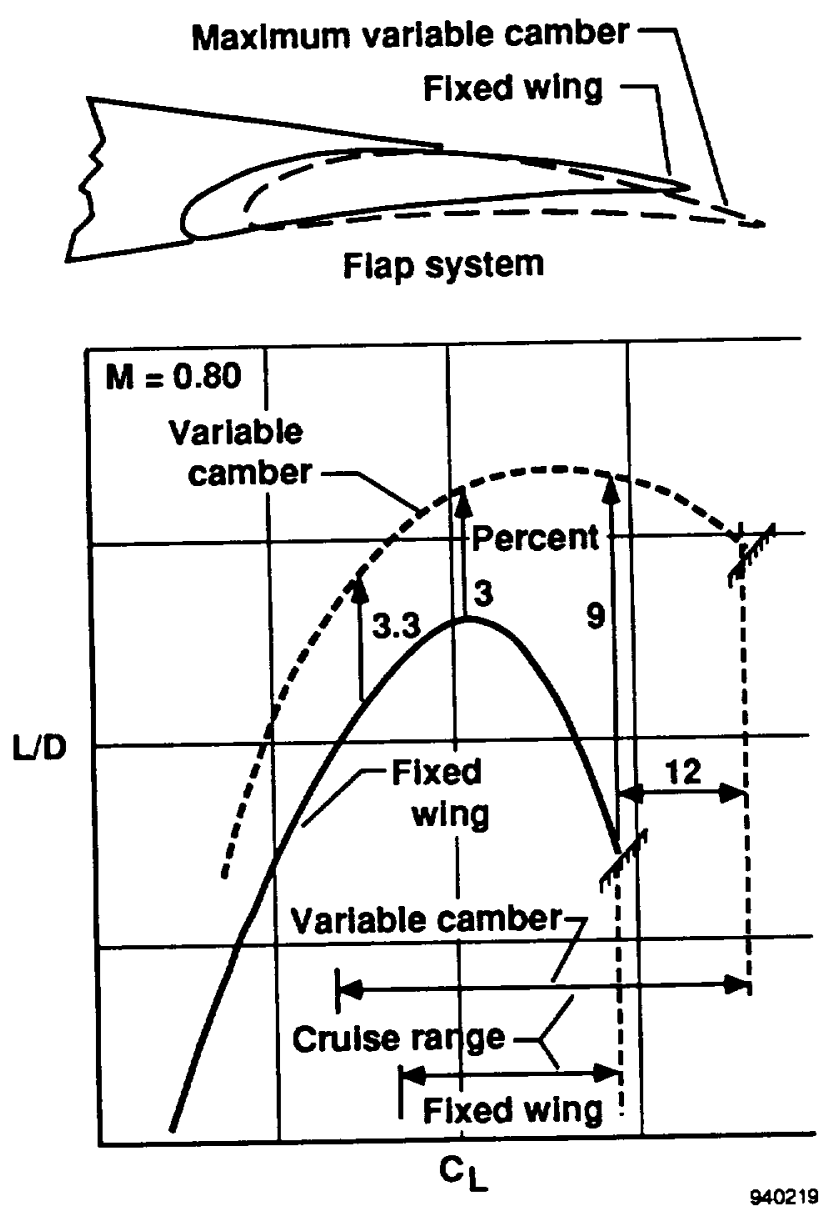

Figure 4. Wind-tunnel data illustrating benefits of a variable-camber system to a transport aircraft using a simple TE flap system. 
increase. For example, a $1^{\circ}$ sideslip on a B-747 requires a fuel-flow increase of 0.75 percent.

Although not in the area of active controls, Airbus has also eliminated the outboard aileron on the A-310 aircraft and the A-300-600 aircraft for drag reduction through system weight reduction and aerodynamic cleanness. Allspeed ailerons and spoilers are used to compensate for the loss of the outboard aileron control power.

\section{Boeing, Douglas, and Lockheed Activities}

As alluded to earlier, Lockheed did much of the pioneering work in the area of active controls for the same reason Airbus currently appears to be the more active leader in this technology area. That is, Lockheed was trying to break into the commercial, transport arena and they had to come up with a better, more efficient product to entice airlines to switch from previous vendors with whom the airlines were, in general, satisfied. Besides the previously discussed active load alleviation and ACEE work, Lockheed also flight tested a system to augment flutter margin on the L-1011 aircraft as part of an ACEE program and flew the L-1011 with an unstable static margin in another program. The results of Lockheed's work are, for the most part, well-documented in the literature. ${ }^{1-3}$

Boeing and Douglas have also performed significant work in the area; however, because of the competitive nature of the business, few discussions of the technical issues surrounding performance optimization are found in the literature.

Both manufacturers have explored the fixed-point rerigging of pitch axis control effectors to achieve drag minimization. Flight programs have determined improved performance with symmetric outboard aileron deflections using fixed-point variable wing cambering. Note that the above are one-shot reriggings and only demonstrate improved performance for a specific flight condition, configuration, or both.

To sum up the activities conducted to date by the various airframe manufacturers, it is accurate to say that they are all interested in optimization of available control surfaces or variables. To date, the manufacturers' main interest has been in hardware modifications (such as rerigging) rather than in active controls technology. The hardware modification approach accrues a portion of the potential improvement available and, of course, does not require new systems capability that would be needed for an active controls approach. One major airframe manufacturer, however, stated that, "Since every aircraft ... flies under its critical design conditions very seldom or only by chance, in the future ... flight aerodynamic efficiency will be further improved at every flight altitude and in all velocity ranges by means of a suitable optimal wing cambering." 25 The importance of small improvements is highlighted by a recent statement by a NASA Associate Administrator, "If you can build an aircraft that saves 1 percent of the fuel per flight over the lifetime of the aircraft, that is a substantial savings. ${ }^{26}$

This review of current transport performance optimization efforts demonstrates that the potential for quasi-steady performance optimization is available. The next section will discuss the application of adaptive control techniques to the performance optimization problem.

\section{Adaptive Control Background}

\section{General}

The application of adaptive control to aircraft problems has been ongoing for more than 30 years with varying degrees of success. These applications have generally centered on handling quality improvements; more recent interest has centered on adaptive performance optimization.

Adaptive control, as applied to flight control, has not found wide acceptance with the aerospace community after initial application on the X-15, F-111, and F-8 digital fly-by-wire aircraft. The lack of interest in adaptive control is due in part to the satisfactory results that have been obtained by conventional design techniques and the lack of an overriding reason to obtain similar results by using a more complex technique. Because most of the required information about the aircraft over its entire envelope is already available, there is very little uncertainty involved in the modeling process. The application of adaptive control is particularly advantageous in areas in which there are significant unknowns about the system and its behavior over its range of operation. Also note that, in many flight control applications, the use of adaptive techniques has led to safety concerns about gain and phase margin reductions, which in turn have contributed to stability and control problems.

Unlike quasi-steady performance optimization, the application of adaptive optimal control to the flight control problem usually centers on optimizing a very subjective, often ill-defined, criteria typically involving flying qualities, i.e., pilot ratings. As such, the application of adaptive control to flying qualities improvement does not take full advantage of the attributes of the methodology. However, the application of adaptive optimal control to quasi-steady performance optimization has clear benefits that are not achievable through control design processes 
that are tailored to handling qualities issues. Quasi-steady performance optimization has well-defined objectives (maximize thrust-drag) and as such, adaptive optimal control is well-suited to it. In addition, application of adaptive optimal control, using a measured performance metric, is insensitive to modeling inaccuracies and measurement biases. (This is unlike PSC, which relied on both accurate models and absolute measurements.) Although safety is also a concern for quasi-steady performance optimization, such issues are more readily addressable for performance optimization due to very low frequency bandwidth operation.

For the Airbus and U.S. cases mentioned previously in which variable-camber performance optimization has been explored, neither devoted serious attention to a transport-class performance optimization algorithm. As stated previously, the AFTI/F-111 MAW system used either predetermined deflection schedules or a real-time trial-and-error approach for camber control. In the Airbus case, only model-based or experimentally determined scheduling is vaguely referenced for camber control.

\section{Performance Seeking Control}

The F-15 PSC program developed a technical approach and methodology that can be used to enhance the performance of fighter and transport (subsonic and supersonic) aircraft. Figure 5 presents a top-level block diagram of the PSC algorithm. It comprises three main modules: estimating, modeling, and optimizing. The F-15 PSC algorithm, however, as currently implemented requires accurate models that predict actual flight hardware performance variations. In addition, the estimation technique depends on accurate absolute measurements of the inputs and outputs of the system being optimized. ${ }^{16}$

The evolution of the F-15 PSC algorithm required continuous improvement of models, which fortunately was possible because of the more than 15 years of experience with the F-100 class of engines and availability of an accurate nonlinear simulation model of the engine. These accurate models (which covered a wide range of degradation) enabled the F-15 PSC algorithm to perform well and, in general, approach the true optimal solution. Measurement biases affect the PSC algorithm because the open-loop model based approach requires accurate absolute measurements. Frequently in control problems, perturbation feedback control techniques are used, and in these cases, biases on measurements do not affect results; however, the F-15 PSC approach is neither perturbation based nor closed loop but rather relies on absolutes and open-loop commands. Several means were explored within the context of the F-15 PSC algorithm, directed at addressing the bias problem, but to no avail. The real-time identification of the biases would be ideal but is not possible because of the

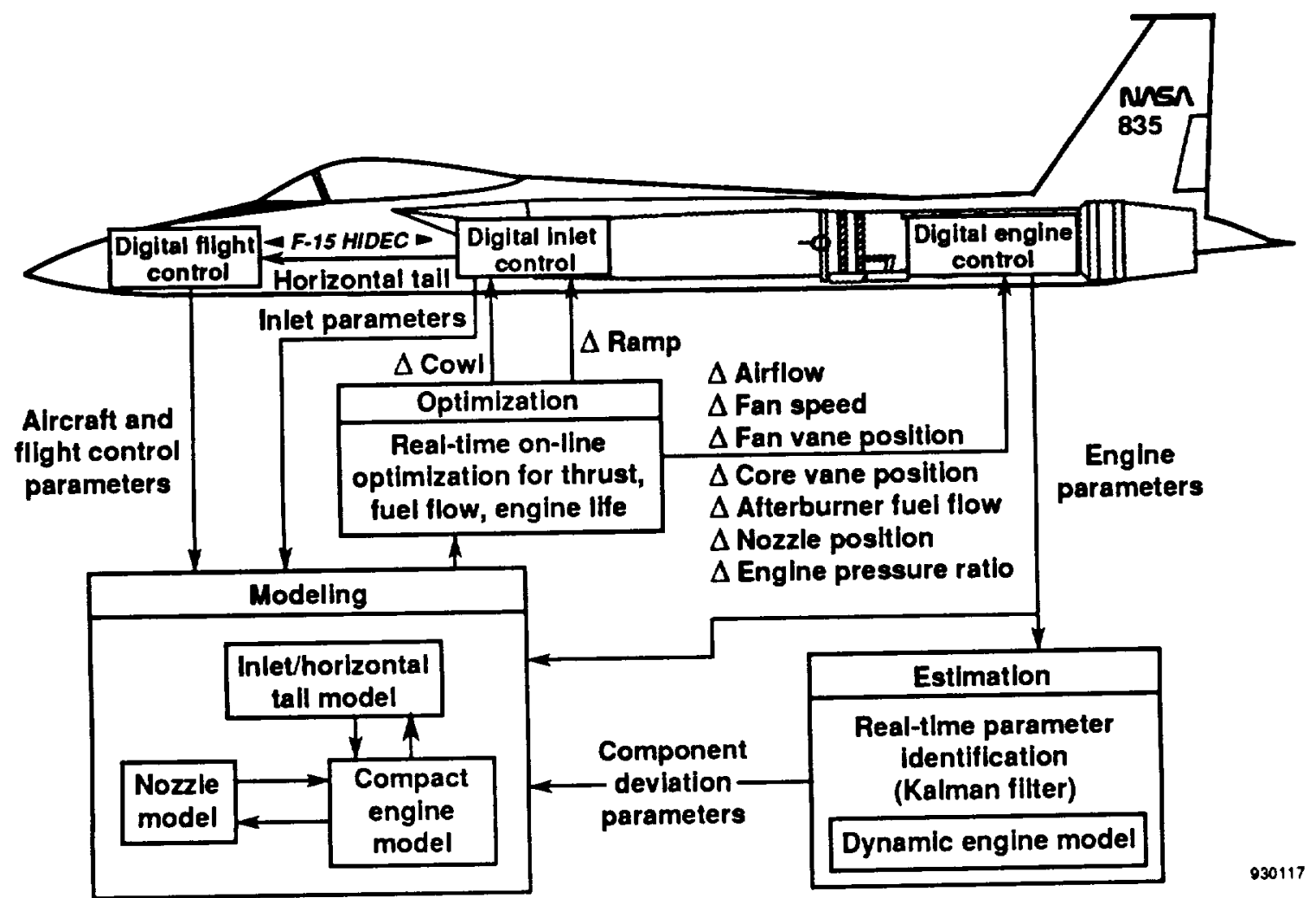

Figure 5. Performance seeking control. 
limited sensor set available. ${ }^{27}$ The solution used to get to flight was a priori identification of key biases from ground-based tests and their inclusion in the flight algorithm. This is far from ideal because each engine has a unique set of biases.

An approach to accommodate the above problems in a systematic way is the application of adaptive optimal techniques, which are not affected by either of the above problems. The adaptive optimal approach is based on real-time estimation of gradients of performance measures to control variables. These gradients are based on flight measurements and not based on predictions; also because gradients are used, the approach will not be sensitive to measurement biases.

The adaptive optimal approach is ideally suited for use in environments where there is a high degree of uncertainty in model and measurement accuracy. This is particularly true for a program that is of limited duration or in its initial flight testing phase; application of adaptive control concepts could be of great advantage for such cases where there is a lack of knowledge about system characteristics. The F-15 PSC approach requires, as a minimum, an aircraft that has had sufficient flight testing to ensure model and measurement system accuracy.

\section{Performance Optimization}

Many issues enter into the performance optimization problem for subsonic transport aircraft. Foremost, there must be the potential for optimization, which implies redundant control effector capability (i.e., more than one means of trimming out the forces and moments to obtain a steady-state flight condition). Most aircraft have significant capability in this area (i.e., redundant control effectors), although taking advantage of this capability is a different issue. Performing optimization from a condition that is already fine-tuned (requiring thousands of hours in the wind tunnel to optimize the aerodynamic configuration $^{24}$ ) places increased demands on high-quality instrumentation to sense small differences in an unsteady environment. Other issues affecting optimization are computational capability, parameter identification or optimization algorithm selection or both, and software-hardware interfacing.

\section{Control Effectors}

Drag minimization potential exists for the entire spectrum of subsonic transport aircraft. As noted previously, aircraft manufacturers have recognized the potential for performance improvements based on available control effectors and have implemented some active control modes as well as fixed-point reriggings based on flight test results.

Nearly all the controls or variables that can potentially play a role in performance optimization for current generation aircraft have been previously mentioned. As shown on figure 6, they include elevator, horizontal stabilizer, outboard aileron, inboard aileron, flaps, slats, rudder, and c.g. In addition, the potential for flightpath control using only differential thrust has been demonstrated. ${ }^{28}$ Spoilers are probably not an option for performance optimization because they only increase drag; although, if a case exists which requires drag modulation, spoilers are a viable controller. Potential selected controlled variable trades are

- Symmetric aileron or flap (LE and TE) or both as a function of horizontal stabilizer

- Inboard in comparison with outboard symmetric aileron or flap or both

- Elevator as a function of horizontal stabilizer

- Inboard in comparison with outboard elevator

- Center of gravity as a function of horizontal stabilizer

- Rudder as a function of differential thrust

- Sideslip as a function of rudder

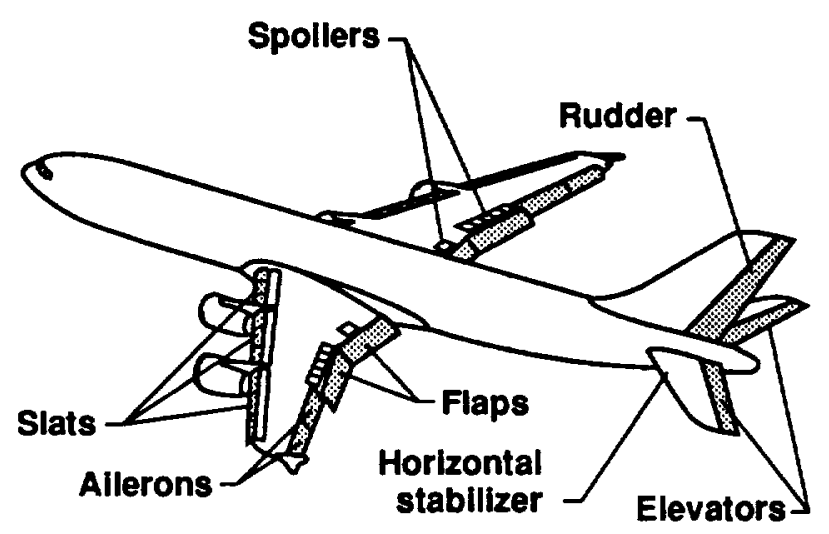

940220

Figure 6. Typical subsonic transport control effectors. 
Note that delta wing configurations generally have less optimization potential because they have fewer independent control effectors; fewer effectors reduce the potential for optimization. The main difference is that there is no independent horizontal stabilizer-elevator for delta-wing configurations, thus removing a major potential for wing optimization. This does not imply that more sophisticated wing leading and trailing edge devices could not be implemented, which would permit some degree of camber optimization. A canard can significantly increase the optimization potential for conventional and delta wing configurations.

\section{Instrumentation}

High-quality, sensitive instrumentation is a requirement for successful implementation of a performance optimization algorithm. Fortunately, the instrumentation being implemented in today's most advanced transports is generally satisfactory. Although a large number of cost functions or variables exists that could conceivably be used for optimization, only a few basic aircraft measurements are required for cruise drag minimization. To minimize fuel flow at constant Mach and altitude conditions requires accurate fuel flow indications such as either fuel flow, fuel valve position, or throttle position. Although in absolute terms the accuracy required would be demanding, the optimization problem only places demands on perturbation accuracy, which is not affected by biases. To maximize velocity for constant altitude and fuel flow requires accurate perturbation measurements of velocity or flightpath acceleration or both. The following states the accuracy goals in terms of resolution for the preliminary design work presented:

\begin{tabular}{ll}
\hline \hline \multicolumn{1}{c}{ Parameter } & \multicolumn{1}{c}{ Resolution } \\
\hline Fuel valve-throttle & $0.5^{\circ}$ or 0.5 percent full travel \\
Fuel flow & $25.0 \mathrm{lb} / \mathrm{hr}$ \\
Acceleration & $0.005 \mathrm{~g}$ \\
Velocity & $0.5 \mathrm{ft} / \mathrm{sec}$ \\
\hline
\end{tabular}

Although not strictly an instrumentation issue, precise control of control effectors is required in cases that require forced excitation to enhance parameter estimation. The control accuracy should be much better than the excitation amplitude which will be discussed in the next scction.

\section{Algorithm Development and Description}

With the objective of improving quasi-steady performance of subsonic transports, NASA Dryden is in the process of researching real-time adaptive performance optimization technology. Ideally, performance optimization could be done using responses to atmospheric excitation. However, with tight pitch-rate, pitch-attitude, and altitude and velocity hold control laws, extemal environment-based disturbances and associated responses would, in general, be very small. Therefore, forced excitation is required to ensure identifiability. The requirement for forced excitation must be tempered by the additional requirement that neither handling or ride qualities are noticeably impacted, which in turn dictates the range of excitation frequencies and amplitudes. Parameter identification of the performance-control sensitivity could be done by any of a number of techniques covering a broad range of sophistication. System optimization is a direct fallout of the parameter identification but due to overall system nonlinearities a real-time solution is required.

Truly pioneering work in the field of optimizing controls was conducted by Draper and Li more than 40 years ago. ${ }^{29}$ In this case power was maximized for an internal combustion engine as a function of ignition timing and fuel-air ratio for constant engine speed and fuel flow. A similar approach was applied by Vasu to maximize a jet engine's pressure ratio. ${ }^{30}$ In this example, which is illustrated in figure 7, output pressure is maximized as a function of fuel flow. Interestingly, this application is very similar to the objective of the first phase of the PSC program,

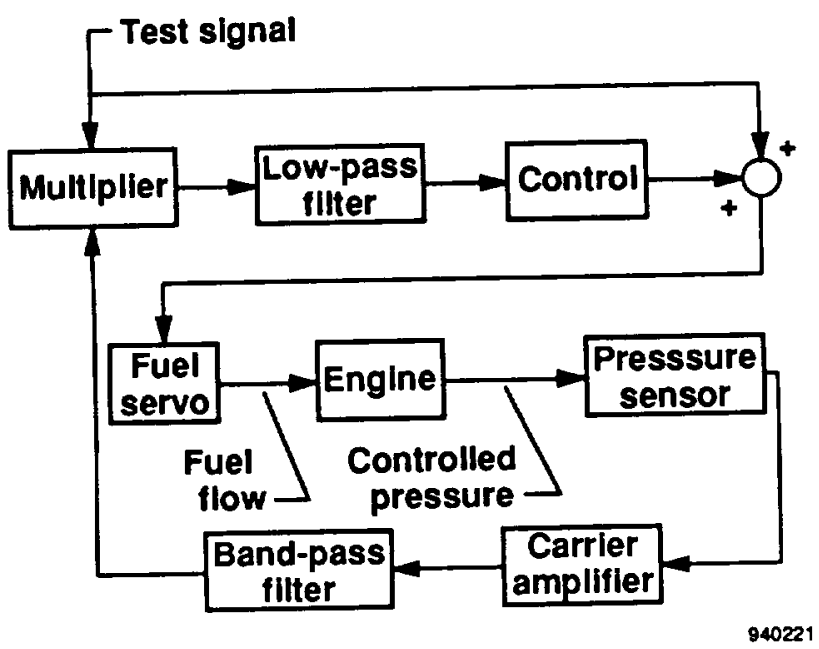

Figure 7. Optimalizer control system for a turbojet engine. 
which was directed at optimizing only propulsion system performance.

This report uses optimizing techniques, similar to those just discussed, for quasi-steady performance optimization algorithm design and evaluation on a first-generation subsonic transport; a B-720 nonlinear model simulation. Specifically, the technique is based on periodic perturbations and subsequent performance gradient estimation with an online approximated correlation measurement between the input perturbation and the measured performance. Because the technique is based on gradients, the technique is insensitive to measurement biases. Moreover, the gradient estimations are based on actual performance measurements, and as such, errors associated with models are not a factor.

Figure 8 presents a block diagram of an algorithm designed to optimize the effective wing camber character- istics via symmetric aileron application. The basic operation is designed to search for the minimum drag point, which also involves horizontal stabilizer-elevator to compensate for wing induced lift and pitching moment changes. The optimization includes the entire aircraft because the various moments and forces must be balanced. The basic optimization concept is quite simple and requires explicit excitation of symmetric aileron and the measured response of the desired performance variable. The performance measure is high passed (removing the low-frequency signal content) and multiplied by the excitation signal (delayed as required) to produce a correlation measure; this is then low passed (removing the highfrequency signal content), integrated, and summed with the excitation command. The correlation process (multiplication) is enhanced by introducing a delay to compensate for any input-output phase shift introduced by the aircraft. The mean value of the symmetric aileron is driven to the point at which correlation between the symmetric aileron

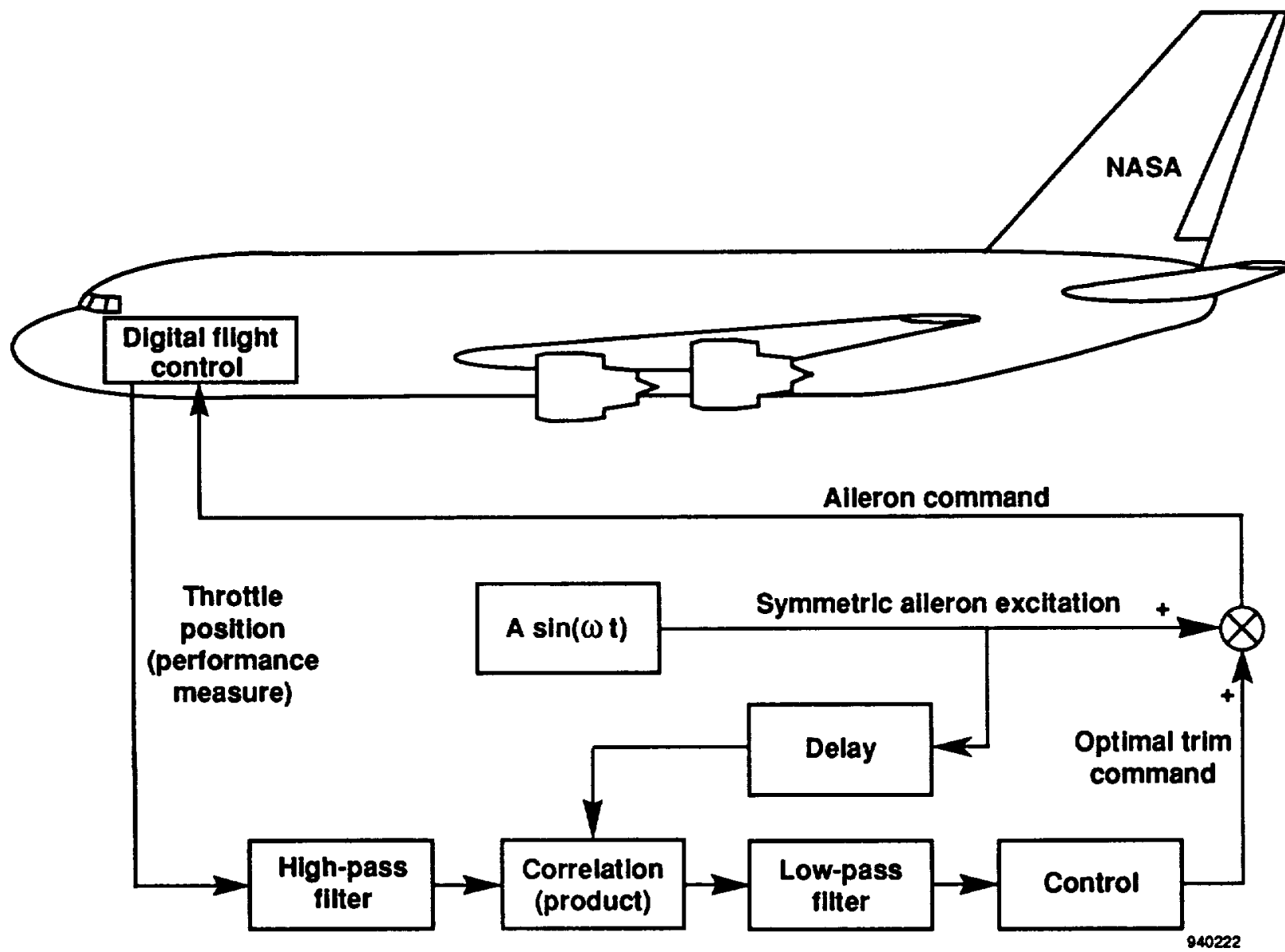

Figure 8. Adaptive optimal performance algorithm; minimum fuel mode. (Autopilot provides inner-loop altitude and velocity control.) 
command and the performance variable is zero, corresponding to the optimal average aileron deflection. Depending exactly on what is desired, one can then take advantage of the reduced drag for increasing velocity or minimizing fuel flow.

\section{Results and Discussion}

\section{Simulation Results}

Initial design work is concerned with cruise-type flight conditions and as such an altitude hold control mode is used to constrain altitude. In the case of maximizing velocity, the optimal performance algorithm is an outerloop of altitude hold. For this mode, longitudinal acceleration or velocity or a blend of the two is the optimal performance measure. Figure 9 presents an example of this mode of operation. The symmetric aileron excitation amplitude of $\pm 2^{\circ}$ was driven at a frequency of $0.025 \mathrm{rad} / \mathrm{sec}$. The intent was to keep the excitation frequency below the dynamics of the inner-loop autopilot mode so that it would not adversely interact with the optimization. The performance parameter is velocity and as can be seen, the velocity increased about $50 \mathrm{ft} / \mathrm{sec}$. (Note that the B-720 simulation was primarily intended for low-speed work and as such the high-speed drag effects are not modeled accurately, which results in a larger-thanexpected speed increase. The only way this miss modeling affects the results is that it takes longer for the velocity to reach its maximum.) Altitude is oscillating $( \pm 15 \mathrm{ft})$ as would be expected, and the frequency is such that the normal acceleration levels are quite small (less than $0.03 \mathrm{~g}$, which is below the neutral passenger response boundary). The symmetric aileron was modeled to have its minimum drag at about $-5^{\circ}$ and is observed to converge to about $-4.5^{\circ}$. The discrepancy is attributed to the difference between wing drag minimization and complete aircraft drag minimization. The three symmetric aileron time histories represent the excitation signal, the controller output, and their sum. The result of the slowly changing optimal symmetric aileron trim command is reflected in minimal angle-of-attack change and an approximately $1^{\circ}$ change in horizontal stabilizer angle. Velocity resolution characteristics of $0.5 \mathrm{ft} / \mathrm{sec}$ were simulated in the optimal controller feedback loop and have no discernible effect on system performance.

For the case in which constant flight conditions are required, an additional inner-loop auto-throttle velocity controller is needed. In this situation, the optimal performance measure is the throttle angle (which is directly correlated with fuel flow); with drag being minimized, the velocity hold mode reduces throttle to maintain the flight
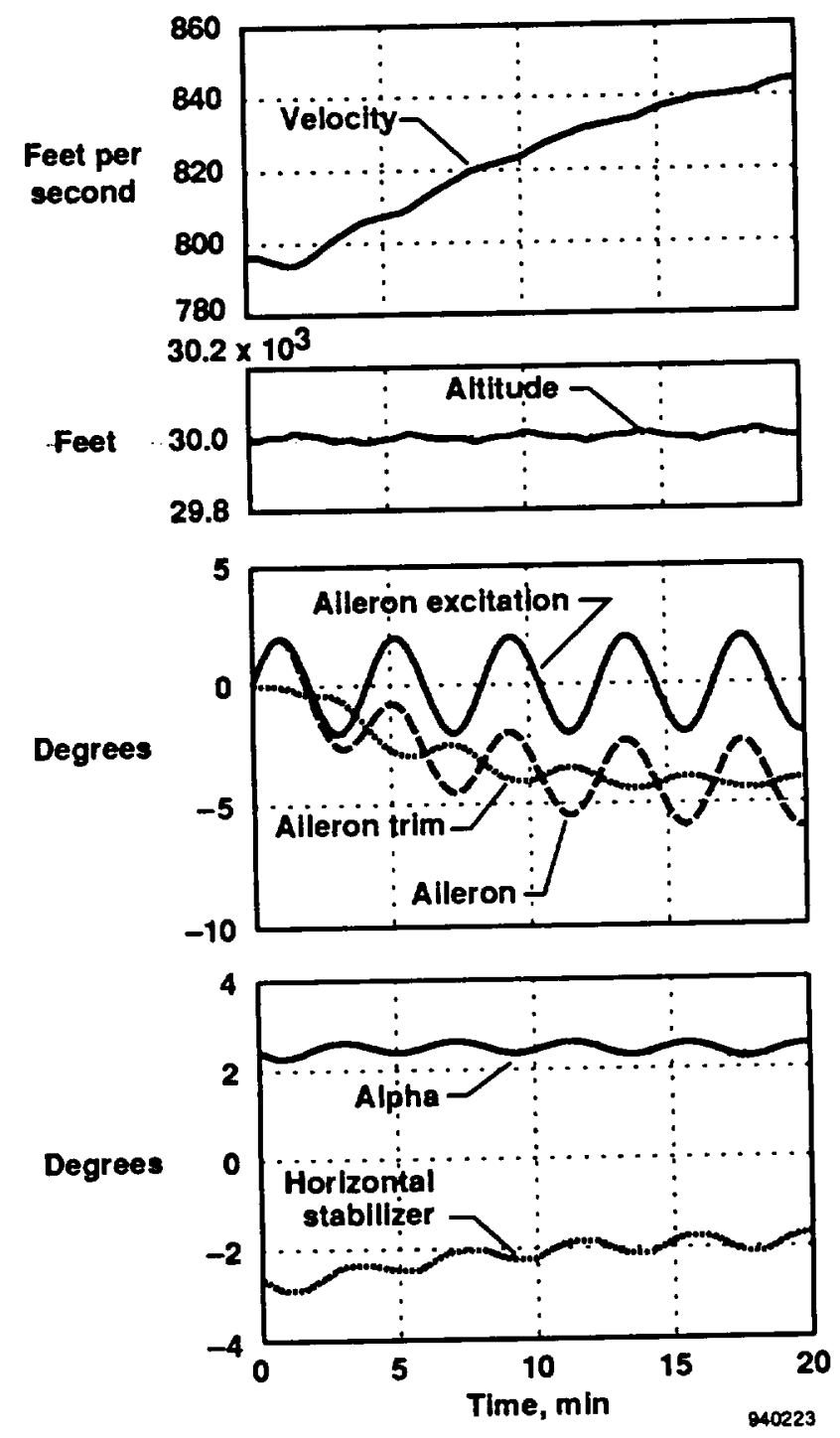

Figure 9. Maximization of speed via drag minimization for the B-720 aircraft; $M=0.80$ at $30,000 \mathrm{ft}$ and gross weight of $200,000 \mathrm{lb}$.

condition. Figure 10 shows an example of this mode of operation. The aileron excitation amplitude and frequency were again $\pm 2^{\circ}$ and $0.025 \mathrm{rad} / \mathrm{sec}$, respectively. In this case, the autothrottle is controlling the velocity very tightly and the altitude is controlled to $\pm 15 \mathrm{ft}$. In this mode the ailerons converge to about $-5^{\circ}$ and the reduced drag results in a thrust required reduction of about 1.5 percent. Velocity and throttle resolution characteristics of $0.5 \mathrm{ft} / \mathrm{sec}$ and $0.5^{\circ}$ were simulated in the velocity-hold inner loop and the optimal controller feedback loop. The effects of throttle resolution are observable on the thrust output.

In both cases, excitation frequency was found to be a critical factor in obtaining satisfactory closed-loop 


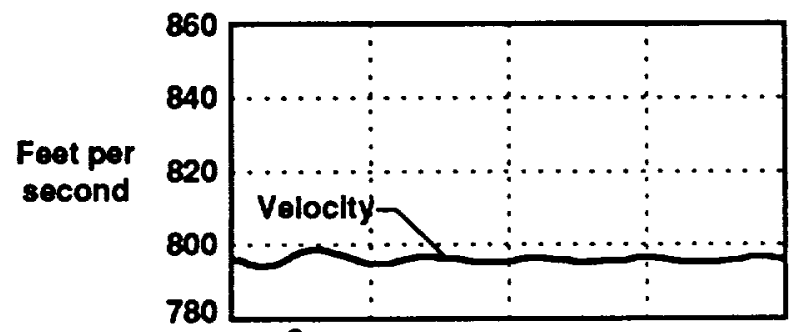

$30.2 \times 10^{3}$

Feet
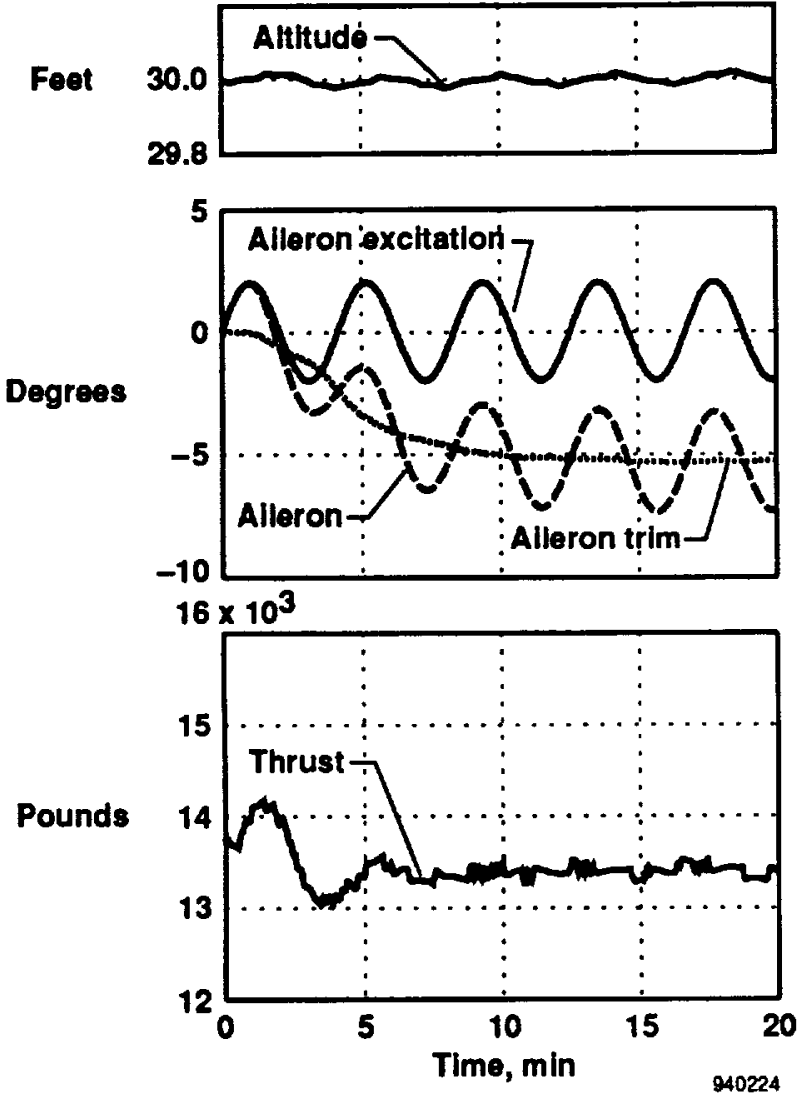

Figure 10. Minimization of throttle angle via drag minimization for the B-720 aircraft; $M=0.80$ at $30,000 \mathrm{ft}$ and gross weight of $200,000 \mathrm{lb}$.

response. Frequencies higher than those used in the examples created stability and convergence problems. For the adaptive optimization approach taken, the excitation frequency must be below the frequency of the aircraft combined with inner-loop autopilot control to avoid unfavorable interactions.

\section{Related Issues}

The forced excitation requirement of real-time adaptive optimization generally attracts concern and, therefore, some discussion is in order. For the very steady conditions of cruise flight for which we are optimizing, forced excitation is the only means of performing identification. adaptive optimization; there is no other means of identifying the aircraft's desired characteristics. The low excitation frequency was selected both to minimize interaction with the autopilot inner-loops as well as to minimize the effect on ride qualities. Continuous excitation does raise a concern for wear and tear, however, relatively few lowamplitude cycles are required to obtain optimality (about five in the example presented) and because aircraft flightconfiguration conditions change slowly, a low- or noactivity mode could be designed into the system for use once the optimal condition is reached. Because aircraftspecific variations play a significant role in the actual amount of performance improvement accruable, using previous optimality results as initial conditions can speed up optimality convergence for subsequent flights.

Because the performance optimization problem is searching for small benefits, instrumentation would appear to be a critical factor. However, realistic resolution and noise effects have been evaluated showing that the algorithm is robust with respect to those characteristics. Different flight conditions have also been evaluated and it appears that very little, if any, algorithm tuning is required. Additional studies are required on a wide-body configuration to ensure that the results presented are applicable to modern transport aircraft.

\section{Concluding Remarks}

All the major airframe manufacturers have explored configuration optimization using existing control effectors. Some findings are being implemented in a fixed-point rerigging fashion. Because the manufacturers are pursuing specific product improvement, these modifications probably accrue a reasonable portion of the optimization potential available (the difference between predictions and actual flight).

A conceptual design of an optimal performance algorithm for application to subsonic transports is presented. Preliminary simulation results indicate the approach is very promising. The algorithm implementation is simple and appears to have robust performance characteristics.

The use of differential thrust, thrust modulation, and thrust vectoring has not been discussed explicitly other than thrust modulation being used for autopilot velocity control. All three can be treated as additional controllers available for optimization similar to that described in the examples presented. One can easily envision an optimal set of effective sideslip angle, bank angle, differential thrust, and rudder deflection to offset common occurrences of aircraft asymmetry (caused by manufacturing or operational conditions or both). 
The technology being developed should be even more applicable to the high-speed civil transport because its performance optimization sensitivities would generally be larger than those for the subsonic transport. The opportunities for the propulsion system to be a major player are significant in the high-speed transport design, while the propulsion system is a minor player for the subsonic transport.

\section{References}

1Johnson, J. F., Accelerated Development and Flight Evaluation of Active Controls Concepts for Subsonic Transport Aircraft-Volume I-Load Alleviation/Extended Span Development and Flight Tests, NASA CR-159097. Sept. 1979.

${ }^{2}$ Guinn, Wiley A., Jerry J. Rising, and Walt J. Davis, Development of an Advanced Pitch Active Control System for a Wide Body Jet Aircraft, NASA CR-172277, Feb. 1984

${ }^{3}$ Rising, Jerry J., Development of a Reduced Area Horizontal Tail for a Wide Body Jet Aircraft, NASA CR-172278, Feb. 1984.

${ }^{4}$ Advanced Fighter Technology Integration F-III Mission Adaptive Wing, NASA CP-3055, proceedings of a symposium held at NASA Ames Center Dryden Flight Research Facility, Edwards, California, Apr. 4-6, 1989. (ITAR restricted document)

5Phillips, Paul W. and Stephen B. Smith, "AFTI/F-111 Mission Adaptive Wing (MAW) Automatic Flight Control System Modes Lift and Drag Characteristics," AFFTC-TR-89-03, May 1989. (Distribution limited to U.S. Government agencies only (Test and Evaluation), April 1989. Other requests for this document shall be referred to the AFTI/F-111 (MAW) Program Office (WRDC/FIMF), Wright-Patterson AFB OH 45433-6503.)

${ }^{6}$ Friend, Edward L., Flight Buffet Characteristics of a Smooth Variable-Camber Mission Adaptive Wing for Selected Wing Flap Deflections, NASA TM-4455, Feb. 1993.

${ }^{7}$ Thomas, Jürgen K. W., "Advanced Technology-The Key To European Competitiveness," lecture presented to the Aeronautical Society of South Africa, Apr. 25, 1984 (A85-21680).

${ }^{8}$ Drachenberg, H., "Weight and Center of Gravity Determination on Ground and Airborne," presented at the 45th Annual Conference of the Society of Allied Weight Engineers, Inc., Williamsburg, Virginia, SAWE paper no. 1695, May 1986 (A87-36281).
${ }^{9} \mathrm{Huber}$, Bernard, "Center of Gravity Control on Airbus Aircraft Fuel, Range and Loading Benefits," presented at the 47th Annual Conference of the Society of Allied Weight Engineers, Inc., Plymouth, Michigan, SAWE paper no. 1843, May 1988.

${ }^{10}$ Horst, Dieter, "Sideslip Indication System as a Fuel Saving Aid in Jet Transport Aircraft Operation," Proceedings of the 11th Symposium on Aircraft Integrated Data Systems, Sept. 1981.

"Szodruch, J., "The Influence of Camber Variation on the Aerodynamics of Civil Transport Aircraft," AIAA Paper No. 85-0353, Jan. 1985.

${ }^{12}$ Renken, J. H., "Mission-Adaptive Wing Camber Control Systems for Transport Aircraft," AIAA paper no. 85-5006, Oct. 1985.

${ }^{13}$ Digital Electronic Engine Control (DEEC) Flight Evaluation in an F-15 Airplane, Proceedings of a minisymposium held at NASA Ames Research Center Dryden Flight Research Facility, Edwards, California, May 25-26, 1983, NASA CP-2298, Mar. 1984.

${ }^{14}$ Myers, L. P., and F. W. Burcham, Jr., Preliminary Flight Test Results of the F100 EMD Engine in an F-15 Airplane, NASA TM-85902, 1984.

${ }^{15}$ Highly Integrated Digital Electronic Control Symposium, Proceedings of a conference held at NASA Ames Research Center Dryden Flight Research Facility, Edwards, Califomia, Mar. 11-12, 1987, NASA CP-3024, 1989.

${ }^{16}$ Gilyard, Glenn B. and John S. Orme, Performance Seeking Control: Program Overview and Future Directions, NASA TM-4531, Aug. 1993.

17 "New Large Aircraft: Big Problems," Flight International, Nov. 24-30, 1993, pp. 34-36.

${ }^{18}$ España, Martín and Glenn Gilyard, “Aircraft Adaptive Performance Optimization Using Redundant Control Effectors," IEEE Journal, Aug. 1994.

${ }^{19}$ Wagenmakers, Joop, Aircraft Performance Engineering-Guidelines from an Aircraft Performance Engineer, Prentice Hall, New York, 1991.

${ }^{20} \mathrm{KC}-135$ Winglet Program Review, Proceedings of a symposium held at Dryden Flight Research Center, Edwards, California, Sept. 16, 1981, NASA CP-2211, 1982.

${ }^{21}$ Gera, J., J. T. Bosworth, and T. H. Cox, X-29A Flight Test Techniques and Results: Flight Controls, NASA TP-3121, May 1991. 
${ }^{22}$ Hicks, John W. and Bryan J. Moulton, Effects of Maneuver Dynamics on Drag Polars of the X-29 ForwardSwept-Wing Aircraft With Automatic Wing Camber Control, NASA TM-100422, June 1988.

${ }^{23}$ Renken, Jürgen, "Variable Wing Camber Control Systems for the Future Airbus Program," Company Report No. MBB-UT-104/88, (in German; English summary) Feb. 1988.

24"Soaring on Intelligent Wings: Aerodynamicists at MBB are Already at Work on Tomorrow's Projects," NewTech News, no. 1, 1989 (A89-43077).

25"MBB Studies Variable-Camber Wing for Airbus," JPRS-WST-85-024, Aug. 1985 (N86-15449).

26"Face to Face With Wesley Harris," Aerospace America, Sept. 1993, p. 6.
${ }^{27}$ España, Martín D. and Glenn B. Gilyard, On the Estimation Algorithm Used in Adaptive Performance Optimization of Turbofan Engines, NASA TM-4551, Dec. 1993.

${ }^{28}$ Gilyard, Glenn B., Joseph L. Conley, Jeanette Le, and Frank W. Burcham, Jr., A Simulation Evaluation of a FourEngine Jet Transport Using Engine Thrust Modulation for Flightpath Control, NASA TM-4324, Sept. 1991.

${ }^{29}$ Draper, C. S. and Y. T. Li, "Principles of Optimalizing Control Systems and an Application to the Internal Combustion Engine," sponsored by the Aeronautical Engineering Department, Massachusetts Institute of Technology, published by the ASME, Sept. 1951.

${ }^{30}$ Vasu, George, "Experiments With Optimalizing Controls Applied to Rapid Control of Engine Pressures With High-Amplitude Noise Signals," Transactions of the ASME, Apr. 1957, pp. 481-488. 



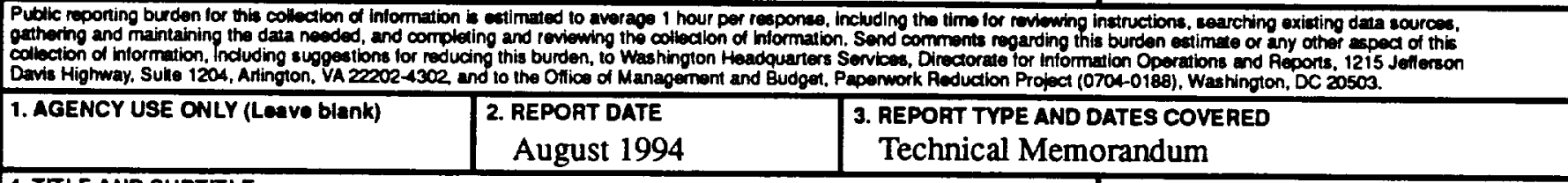

4. TITLE AND SUBTITLE

5. FUNDING NUMBERS

On The Use Of Controls For Subsonic Transport Performance Improvemnent: Overview And Future Directions

6. AUTHOR(S)

Glenn Gilyard and Martín Espafia, NASA Dryden Flight Research Center,

Edwards, CA

WU 505-69-10

7. PERFORMING ORGANIZATION NAME(S) AND ADDRESS(ES)

8. PERFORMING ORgaNIZATION REPORT NUMBER

NASA Dryden Flight Research Center

P.O. Box 273

Edwards, Califomia 93523-0273

$\mathrm{H}-2002$

9. SPONSORING/MONOTORING AGENCY NAME(S) AND ADDRESS(ES)

10. SPONSORINGMONITORING

AGENCY REPORT NUMBER

National Aeronautics and Space Administration

Washington, DC 20546-0001

NASA TM-4605

11. SUPPLEMENTARY NOTES

This originally appeared as AIAA-94-3515 for the Atmospheric Flight Mechanics Conference, Scottsdale, Arizona, August 1-3, 1994.

12a. DISTRIBUTION/AVAILABILITY STATEMENT

12b. DISTRIBUTION CODE

Unclassified--Unlimited

Subject Category 02, 03

13. ABSTRACT (Maximum 200 words)

Increasing competition among airline manufacturers and operators has highlighted the issue of aircraft efficiency. Fewer aircraft orders have led to an all-out efficiency improvement effort among the manufacturers to maintain if not increase their share of the shrinking number of aircraft sales. Aircraft efficiency is important in airline profitability and is key if fuel prices increase from their current low. In a continuing effort to improve aircraft efficiency and develop an optimal performance technology base, NASA Dryden Flight Research Center developed and flight tested an adaptive performance seeking control system to optimize the quasi-steady-state performance of the F-15 aircraft. The demonstrated technology is equally applicable to transport aircraft although with less improvement. NASA Dryden, in transitioning this technology to transport aircraft, is specifically exploring the feasibility of applying adaptive optimal control techniques to performance optimization of redundant control effectors. A simulation evaluation of a preliminary control law optimizes wing-aileron camber for minimum net aircraft drag. Two submodes are evaluated: one to minimize fuel and the other to maximize velocity. This paper covers the status of performance optimization of the current fleet of subsonic transports; available integrated controls technologies are reviewed to define approaches using active controls. A candidate control law for adaptive performance optimization is presented along with examples of algorithm operation.

\begin{tabular}{|c|c|c|c|}
\hline \multirow{2}{*}{\multicolumn{3}{|c|}{$\begin{array}{l}\text { 14. SUBJECT TEAMS } \\
\text { Drag reduction, Fuel consumption, Flight optimization, Aircraft performance, Opti- } \\
\text { mization, Cambered wings, Optimal control }\end{array}$}} & \multirow{2}{*}{$\begin{array}{l}\text { 15. NUMBER OF PAGES } \\
17 \\
\begin{array}{l}\text { 16. PRICE COOE } \\
\text { AO3 }\end{array}\end{array}$} \\
\hline & & & \\
\hline $\begin{array}{l}\text { 17. SECUAITY CLASSIFICATION } \\
\text { OF REPORT }\end{array}$ & $\begin{array}{l}\text { 18. SECUAITY CLASSIFICATION } \\
\text { OF THIS PAGE }\end{array}$ & $\begin{array}{l}\text { 19. SECURTY CLASSIFICATION } \\
\text { OF ABSTRACT }\end{array}$ & 20. LIMTTATION OF ABSTRACT \\
\hline Unclassified & Unclassified & Unclassified & Unlimited \\
\hline
\end{tabular}

